\title{
Actualisering AIS en ROA prognoses tot 2022
}

Citation for published version (APA):

Bakens, J., Dijksman, S., \& Fouarge, D. (2018). Actualisering AIS en ROA prognoses tot 2022. ROA.

ROA Fact Sheets No. 019 https://doi.org/10.26481/umarof.2018019

Document status and date:

Published: 01/01/2018

DOI:

10.26481/umarof.2018019

Document Version:

Publisher's PDF, also known as Version of record

\section{Please check the document version of this publication:}

- A submitted manuscript is the version of the article upon submission and before peer-review. There can be important differences between the submitted version and the official published version of record.

People interested in the research are advised to contact the author for the final version of the publication, or visit the DOI to the publisher's website.

- The final author version and the galley proof are versions of the publication after peer review.

- The final published version features the final layout of the paper including the volume, issue and page numbers.

Link to publication

\footnotetext{
General rights rights.

- You may freely distribute the URL identifying the publication in the public portal. please follow below link for the End User Agreement:

www.umlib.nl/taverne-license

Take down policy

If you believe that this document breaches copyright please contact us at:

repository@maastrichtuniversity.nl

providing details and we will investigate your claim.
}

Copyright and moral rights for the publications made accessible in the public portal are retained by the authors and/or other copyright owners and it is a condition of accessing publications that users recognise and abide by the legal requirements associated with these

- Users may download and print one copy of any publication from the public portal for the purpose of private study or research.

- You may not further distribute the material or use it for any profit-making activity or commercial gain

If the publication is distributed under the terms of Article $25 \mathrm{fa}$ of the Dutch Copyright Act, indicated by the "Taverne" license above, 
Maastricht University ROA

\section{Actualisering AIS en ROA prognoses tot 2022}

\section{ROA Fact Sheet}

ROA-F-2018/19

Researchcentrum voor Onderwijs en Arbeidsmarkt | ROA Research Centre For Education and the Labour Market / ROA 


\section{Actualisering AIS en ROA prognoses tot 2022}

\section{Inleiding ${ }^{1}$}

In december 2017 publiceerde het rapport 'De arbeidsmarkt naar opleiding en beroep tot 2022.2 In de daarin gepresenteerde prognoses werd geen rekening gehouden met eventuele actuele veranderingen in overheidsuitgaven of overheidsbeleid, of voornemens voor veranderingen in overheidsuitgaven door het nieuw kabinet omdat informatie hierover niet beschikbaar was ten tijde van het schrijven van het rapport.

In de zomer van 2018 heeft ROA gewerkt aan de actualisering van de prognoses en voor zover mogelijk, afhankelijk van de beschikbaarheid van data, aan de actualisering van de indicatoren over de actuele arbeidsmarktsituatie in het ArbeidsmarktInformatieSysteem (AIS, http://roastatistics.maastrichtuniversity.nl/). Een overzicht van de geactualiseerde variabelen is te vinden in de bijlage.

\section{Actualisering van de uitbreidingsvraag}

Bij de actualisering van de arbeidsmarktprognoses is uitgegaan van de Centraal Economisch Plan (CEP) $2018^{3}$ en de december 2017 bevolkingsprognoses van CBS. ${ }^{4}$ Deze gaan uit van een hogere economische groei op korte termijn ten opzichte van de in december gepubliceerde prognoses $(3,2 \%$ in 2018 en $2,7 \%$ in 2019 in plaats van $1,8 \%$ en $1,7 \%$ ). Voor de jaren daarna wordt uitgegaan van een structurele groei van 1,7\%. Dit is onveranderd ten opzichte van de in december gebruikte cijfers omdat er geen update heeft plaatsgevonden van de middellange termijn verwachte groei door CPB. De CPB macroeconomische ramingen zijn door SEOR op verzoek van het ROA gedifferentieerd naar 21 bedrijfssectoren. ${ }^{5}$ Deze sectorale prognoses zijn afgestemd op de sectorprog-

1 Deze factsheet is tot stand gekomen als onderdeel van het Project Onderwijs-Arbeidsmarkt (POA; http://roa.sbe.maastrichtuniversity.nl/?portfolio=poa-project-onderwijs-arbeidsmarkt-2), mede dankzij financiering van NRO (dossiernummer 405-17-900), UWV, S-BB en Randstad.

2 ROA (2017). De Arbeidsmarkt naar Opleiding en Beroep tot 2022. Maastricht: ROA-R-2017/10 http://roa.sbe.maastrichtuniversity.nl/roanew/wp-content/uploads/2018/01/ ROA R 2017 10.pdf.

3 https://www.cpb.nl/agenda/publicatie-centraal-economischplan-cep-2018

4 https://www.cbs.nl/nl-nl/maatwerk/2017/52/bevolkingsprognose-2017-2060

5 De in december 2017 gebruikte sectorprognoses waren doorgerekend door Panteia. noses van het UWV. Dit moet zorgen voor een goede vergelijkbaarheid tussen ROA en UWV cijfers.

De sectorprognoses zijn gebruikt voor de doorrekening van de verwachte uitbreidingsvraag naar sector (zie tabel 1), beroep en opleiding. De gebruikte methodiek is verder niet aangepast. ${ }^{6}$ De overige componenten van de prognoses (verwachte vervangingsvraag, verwachte instroom, kortdurige werkloosheid) zijn niet bijgesteld ten opzichte van de in december gepubliceerde prognoses.
6 Bakens, J., Bijlsma, I., Cörvers, F., Dijksman, S., Fouarge, D., \& Poulissen, D. (2018). Methodiek arbeidsmarktprognoses en -indicatoren 2017-2022. Maastricht: ROA-TR-2018/4. https://cris. maastrichtuniversity.nl/portal/files/26265556/ROA_TR_2018_5. $\underline{\text { pdf }}$ 


\section{Fact Sheet \\ ROA-F-2018/19}

TABEL 1.

Ontwikkeling van het aantal werkenden per bedrijfssector 1996-2016, en de uitbreidingsvraag naar bedrijfssector 2017-2022, gemiddelde jaarlijkse groep in beide gevallen als percentage van het basisjaar (2016)

\begin{tabular}{|c|c|c|c|}
\hline & & & Werkgelegenheidsontwikkeling \\
\hline & Aantal werkenden gem. & Feitelijk & Prognose \\
\hline & $2015-2016$ & $1996-2016 \%$ & $2017-2022 \%$ \\
\hline Landbouw, bosbouw en visserij & 177.500 & $-0,6$ & $-0,3$ \\
\hline Voedings- en genotmiddelenindustrie & 140.000 & $-1,3$ & 0,4 \\
\hline Chemische industrie & 126.500 & $-1,2$ & $-0,1$ \\
\hline Metaalindustrie & 287.000 & $-1,5$ & 0,8 \\
\hline Overige industrie & 255.500 & $-0,8$ & $-1,2$ \\
\hline Energie & 75.000 & 0,8 & 1,0 \\
\hline Bouwnijverheid & 407.000 & 1,0 & 2,7 \\
\hline Detailhandel & 863.000 & 1,2 & 0,4 \\
\hline Groothandel & 408.000 & $-1,2$ & 0,9 \\
\hline Vervoer en opslag & 373.000 & 1,2 & 0,4 \\
\hline Horeca & 364.500 & 2,1 & 1,8 \\
\hline Informatie en communicatie & 275.500 & 2,3 & 3,4 \\
\hline Financiële dienstverlening en onroerend goed & 337.500 & 0,0 & $-0,4$ \\
\hline Specialistische zakelijke dienstverlening & 599.500 & 2,4 & 0,7 \\
\hline Verhuur en overige zakelijke dienstverlening & 460.500 & 0,7 & 0,7 \\
\hline Openbaar bestuur en overheidsdiensten & 487.500 & 0,5 & 0,5 \\
\hline Onderwijs & 569.000 & 1,7 & 0,7 \\
\hline Zorg & 584.000 & 2,7 & 3,1 \\
\hline Welzijn & 733.000 & 2,3 & 0,9 \\
\hline Cultuur sport en recreatie & 173.000 & 3,3 & 1,7 \\
\hline Overige dienstverlening, huishoudens en extraterritoriale organisaties & 195.500 & 0,8 & 0,0 \\
\hline Totaal (incl. overig) & 8.348 .500 & 0,9 & 1,1 \\
\hline
\end{tabular}




\section{Actualisering AIS en ROA prognoses tot 2022}

\begin{tabular}{|c|c|c|c|}
\hline \multicolumn{4}{|c|}{$v=$ inhoud is bijgewerkt } \\
\hline \multicolumn{4}{|c|}{$x=$ inhoud is bij gebrek aan nieuwe brondata niet bijgewerkt } \\
\hline \multirow[t]{12}{*}{ v } & Bedrijfssector & & \\
\hline & V & Actuele arbeidsmarktsituatie & EBB gemiddelde 2016-2017 \\
\hline & $x$ & Arbeidsomstandigheden & SCP AAP 2014 \\
\hline & $x$ & Vacaturegegevens & SCP AVP 2015-2016 \\
\hline & $x$ & Conjunctuurgevoeligheid & Prognoses tot 2022 \\
\hline & V & Uitbreidingsvraag tot 2022 & Update uitbreidingsvraag \\
\hline & v & Belangrijkste beroepsgroepen & EBB gemiddelde 2016-2017 \\
\hline & $x$ & Belangrijkste opleidingstypen & EBB gemiddelde 2015-2016 \\
\hline & v & Verwachte knelpunten opleiding & bijgewerkt met update prognose \\
\hline & v & Verwachte knelpunten beroep & bijgewerkt met update prognose \\
\hline & $x$ & Kernvaardigheden & PIAAC 2012 \\
\hline & $x$ & Classificatie & \\
\hline \multirow[t]{7}{*}{ v } & Beroepsgroep & & \\
\hline & v & Actuele arbeidsmarktsituatie & EBB gemiddelde 2016-2017 \\
\hline & v & Arbeidsmarktprognoses tot 2022 & Update uitbreidingsvraag, baanopeningen en indicatoren \\
\hline & v & Belangrijkste bedrijfssectoren & EBB gemiddelde 2016-2017 \\
\hline & $x$ & Belangrijkste opleidingstypen & EBB gemiddelde 2015-2016 \\
\hline & $x$ & Kernvaardigheden & PIAAC 2012 \\
\hline & v & Classificatie & \\
\hline \multirow[t]{9}{*}{ v } & Opleidingstype & & \\
\hline & $x$ & Actuele arbeidsmarktsituatie & EBB gemiddelde 2015-2016 \\
\hline & v & Arbeidsmarktprognoses tot 2022 & Update uitbreidingsvraag, baanopeningen en indicatoren \\
\hline & $x$ & Concurrentie-index & EBB gemiddelde 2015-2016 \\
\hline & $\mathrm{x}$ & Belangrijkste beroepsgroepen & EBB gemiddelde 2015-2016 \\
\hline & $x$ & Belangrijkste bedrijfsectoren & EBB gemiddelde 2015-2016 \\
\hline & v & Schoolverlatersgegevens & SIS 2017 \\
\hline & v & Leerlingen en gediplomeerden & DUO 2017 \\
\hline & $\mathrm{x}$ & Classificatie & \\
\hline \multirow[t]{11}{*}{ v } & Arbeidsmarktregio & & \\
\hline & v & Bedrijfssector & \\
\hline & & $\checkmark$ Actuele arbeidsmarktsituatie & EBB gemiddelde 2016-2017 \\
\hline & & x Specialisatie & EBB gemiddelde 2015-2016 \\
\hline & & x Uitbreidingsvraag tot 2022 & Prognoses tot 2022 \\
\hline & v & Beroepsklasse & \\
\hline & & v Actuele arbeidsmarktsituatie & EBB gemiddelde 2016-2017 \\
\hline & & x Specialisatie & EBB gemiddelde 2015-2016 \\
\hline & $x$ & Opleidingscategorie & \\
\hline & & x Actuele arbeidsmarktsituatie & EBB gemiddelde 2015-2016 \\
\hline & & x Arbeidsmarktprognoses tot 2022 & Prognoses tot 2022 \\
\hline
\end{tabular}




\section{Colofon}

(c) Researchcentrum voor Onderwijs en Arbeidsmarkt Niets uit deze uitgave mag op enige manier worden verveelvoudigd zonder voorafgaande schriftelijke toestemming van de directeur van het ROA.

Deze factsheet maakt onderdeel uit van het 'Project OnderwijsArbeidsmarkt' bekostigd door NRO (dossiernummer 405-17900), UWV, S-BB en Randstand.

Researchcentrum voor Onderwijs en Arbeidsmarkt

Maastricht University

School of Business and Economics

secretary-roa-sbe@maastrichtuniversity.nl www.roa.nl

\section{Vormgeving}

ROA secretariaat, Maastricht 